\title{
SPORCULARDA SIVI DENGESI VE PERFORMANSA ETKISI
}

\author{
Onur ÇIRAK ${ }^{1}$ \\ Funda Pınar ÇAKIROĞLU²
}

\section{ÖZET}

Vücutta gerçekleşen bütün biyokimyasal ve fizyolojik fonksiyonlar vücudun sıvı dengesine bağlıdır. Yetersiz sıvı alımı, çevre şartları ve fiziksel aktivitelerin yapılması vücut sıvı dengesini bozmaktadır. Özellikle antrenman veya egzersiz yapan sporcular terlemeye bağlı olarak ciddi miktarlarda sıvı ve elektrolit kaybederler. Kaybedilen sıvı ve elektrolitlerin yerine konması sporcunun, sağlığı ve performansının korunması için son derece önemlidir. Vücut sıvıları azaldıkça performansta düşüş, termoregülasyonda bozulma, sıcağa toleransın azalması vb. çeşitli fizyolojik durumlar ortaya çıkar. Bu durumlardan korunmak ve düzeltmek için sporcuların gün içerisinde düzenli olarak belirli aralıklarla sıvı tüketmeye özen göstermesi; antrenman öncesi, sırası ve sonrası da kendilerine özel bir sıvı alım planı oluşturup uygulamaları gerekmektedir. Bu derleme yazı vücut sıvı dengesinin atletik performans ile arasındaki mekanizmanın ve etkilerinin değerlendirilmesi amacıyla hazırlanmıştır.

Anahtar Kelimeler: Atletik performans, Egzersiz, Hidrasyon, Dehidrasyon

\section{Fluıd Balance And Its Effect On Performance In Athletes}

\section{Abstract}

All the biochemical and physiological functions that take place in the body depend on the fluid balance of the body. Inadequate fluid intake, environmental conditions and physical activity disrupt the body fluid balance. Athletes, especially those who practice or exercise, lose fluid and electrolyte in significant amounts due to sweating. Replacement of lost fluids and electrolytes is extremely important for the athlete's health and performance. As the body fluids decrease, the performance decreases, the thermoregulation deteriorates, the the tolerance of the temperature decreases and various physiological conditions arise. In order to protect and improve these situations, athletes should take regular measures to consume liquids at regular intervals throughout the day. And they need to create and apply a special fluid intake plan before, during and after training. This review is designed to evaluate the mechanics and effects of body fluid balance on athletic performance.

Keywords: Athletic performance, Exercise, Hydration, Dehydration

1 Araş. Gör. Ankara Üniversitesi Sağlık Bilimleri Fakültesi, Beslenme ve Diyetetik Bölümü, onrcrk@hotmail.com

2 Prof.Dr. Ankara Üniversitesi Sağlık Bilimleri Fakültesi, Beslenme ve Diyetetik Bölümü, scakir64@hotmail.com 


\section{GíRiş}

En önemli besin ögesi olarak kabul edilen su, vücudun yaklaşık olarak \%60'ını oluşturmaktadır. Diğer besin ögelerinin eksikliğinin zararları günler, haftalar, aylar hatta yıllar sonra ortaya çıkmasına rağmen, insanların sadece birkaç gün susuz olarak yaşayabildikleri bilinmektedir. ${ }^{1}$, ${ }^{2} \mathrm{Su}$, bedenin iyi ve mükemmel bir şekilde çalışır kalması için gerekli olan kalorisiz bir besin öğesidir. Vücut suyunun sadece \%10'unun kaybı sağlığa ciddi risk teşkil etmektedir. ${ }^{3}$ Bir sporcunun yeterli sıvı alıp almaması şüphesiz sağlığını, vücut ağırlığını, kompozisyonunu, toparlanma süresini ve egzersiz performansını etkileyebilir. Egzersiz performanslarını maksimize etmek isteyen sporcular iyi beslenmeli ve hidrasyonu sağlamalıdır. Bir sporcunun optimal seviyede performans sergilemesi için, bütün beden sistemleri en iyi şekilde çalışıyor olmalıdır. $\mathrm{Bu}$ da protein, karbonhidrat, yağ, vitamin ve mineral gibi çeşitli besin ögelerinin yenmesi ile başarılır. Besin ögelerinin hepsinin ayrı ayrı önemi olmakla birlikte sporcu beslenmesindeki en önemli faktör sudur. Uygun hidrasyon sağlamadan, sporcu en iyi performansını sergileyemez. ${ }^{4,5} \mathrm{Su}$ vücuttaki kimyasal tepkimeler, hücre içindeki mekanizmalar, vücuda özellikle kas hücrelerine besin ögelerinin ve diğer maddelerin taşınması, termoregülasyon, atık ögelerin uzaklaştırıması, eklem yerlerinin kayganlaştırılması, kandaki elektrolitlerin düzenlenmesi ve diğer bir çok fizyolojik sürecin gerçekleşmesini sağlar. ${ }^{2,3,5}$ Bu çalışmada sporcularda sıvı dengesinin nasıl sağlanması gerektiği ve sıvı dengesinin performansa etkilerinin incelenmesi amaçlanmıştır.

\section{En Önemli Sıvı; Su}

Su hayatın sürdürülebilmesi için elzem bir ögedir. İnsan vücudunun yaklaşık olarak \%60'ını oluşturan su, bebeklerde vücudun \%75'ini, yaşlılarda ise $\% 55$ 'ini oluşturmaktadır. ${ }^{6}$ Su hücrelerin, dokuların ve organların yapısına katılmaktadır. Makro besin ögelerinin parçalanması su varlığında gerçekleşir. Glukoz ve amino asitler suyun içinde çözünür ve vücutta dolaşımı sağlanır. Atık maddeler hücre ve dokulardan uzaklaştııır. Hücreler arasında madde geçişine yardımcı olur. Vücuttaki bütün doku ve organların çalışabilmesi için gerekli olan vasküler volümün korunmasını ve kan dolaşımını sağlar. Kardiyovasküler, solunum, sindirim ve üreme sistemi ile böbrek, karaciğer, beyin ve periferal sinir sisteminin etkin bir şekilde çalışabilmesi için ortamda yeterli miktarda su bulunması gerekmektedir. Bunlara ek olarak su, sıcak ve soğuk havalarda termoregulasyonu sağlamakta, eklemler 
arasındaki yüzeyleri sararak kayganlaştırıcı etkisiyle eklemlerin zarar görmesini önlemede ve darbe alınması durumlarında darbelere karşı koruyucu etki göstermektedir. ${ }^{7}$ Suyun sağlık, vücut kompozisyonu, atletik performans üzerinde önemli etkileri olup; vücutta gerçekleşen bütün kimyasal ve biyokimyasal olaylar suya bağımlıdır. ${ }^{6}$

\section{Sivı Dengesi}

Vücut suyu dengesi günlük sıvı alım ve sıvı kaybına bağlıdır. ${ }^{2}$ Suyun kaynakları, içecekler, besinler ve vücudun genel metabolizması tarafından üretilen sudur. Tüm bu su miktarı, ürin, feçes, ter ve ciğerlerden elimine edilen su buharı olarak atılan günlük sıvı kayıplarını karşılamalıdır. Suyun çoğunluğu (ağırlığının \%72'si sudur) kaslarda depolanır. ${ }^{3}$

Vücudun fizyolojik fonksiyonlarını tam olarak yerine getirebileceği kadar sıvı olmasına öhidrasyon denmektedir. Sıvı alımına bağlı olarak vücut sıvılarının olması gereken düzeyden daha fazla olması, hiperhidrasyon, daha az olması hipohidrasyon olarak tanımlanmaktadır. Dehidrasyon ise yetersiz sıvı alımı, terle kayıplar vb. nedenlerden ötürü vücut sıvılarının olması gereken düzeyden daha az olması ya da vücudun öhidrasyon durumundan hipohidrasyon durumuna geçmesi olarak tanımlanabilir. Hem hipohidrasyon hem de hiperhidrasyon performansı olumsuz olarak etkilemektedir., ${ }^{1,8}$

Egzersiz sonucunda vücuda fazladan bir yük bindiğinden dolayı bu mekanizmaların etkin bir şekilde çalışmasında vücut su dengesinin sağlanması çok önemlidir. Bu nedenle sporcular ve fiziksel aktif bireylerin sıvı tüketimine özen göstermesi gerekmektedir. ${ }^{2}$ Vücut sıvılarının yetersiz olması veya aşırı sıvı tüketimi hem sağlığa hem de spor performansı üzerinde olumsuz etkilere sahiptir. Sıvı kaybı özellikle sıcak veya nemli ortamlarda antreman yapan sporcularda ölümle sonuçlanabilecek kadar ciddi bir durumdur.2, 9, 10 Egzersiz süresince kaybedilen sıvının yerine konması dehidrasyonu önlemek ve sakatlanmalardan kaçınmak kadar performansı korumada da gereklidir. Çok az düzeyde dehidrasyon bile, atletik performansı olumsuz yönde etkileyen kas ve beden bitkinliği ile sonuçlanabilir. ${ }^{5}$ Sporcuların antrenman sonrası tartılarak kaybettikleri sıvı miktarını belirlemeleri, idrar renklerini gözlemeleri veya susuzluk düzeylerini takip etmeleri sıvı kaybının yerine konmasına yardımcı olmaktadır. ${ }^{2}$ 
Vücut sıvı dengesinin sağlanmasında $\mathrm{Na}^{+}, \mathrm{K}^{+}, \mathrm{Ca}^{++}, \mathrm{Mg}^{++}, \mathrm{Cl}^{-}$ mineralleri etkin bir role sahiptir. ${ }^{2,} 4$ SıVı dengesinin sağlanmasında kaybedilen su kadar, sodyum gibi kaybedilen elektrolitlerin yerine konması son derece önemlidir. ${ }^{2,10}$ Vücut sıvılarının dengede tutulmasında en önemli elektrolitler $\mathrm{Na}^{+}, \mathrm{Cl}^{-}$ve $\mathrm{K}^{+\prime}$ dur. Vücutta yeterli elektrolit bulunmadığında, kas krampları, halsizlik ve apatiyi de içeren yetersizlik semptomları gözlenebilir. ${ }^{3}$ Diğer taraftan fazla sıvı alımına bağlı olarak $\mathrm{Na}$ atımı artmakta ve hiponatremi gözlenebilmekte ve vücudun su tutma kapasitesi düşmektedir. ${ }^{11}$

\section{Dehidratasyonun Nedenleri}

Ağır fiziksel aktivite, sıvı alımının kısıtlanması, sıcak veya nemli bir ortama maruz kalmak veya diüretik kullanımı gibi çeşitli faktörler dehidratasyona neden olur. Dehidratasyon sonucunda vücut sıvılarındaki azalmaya bağlı olarak susama hissi oluşmaktadır. ${ }^{12}$ Susama doğadaki tüm canlıların vücut sıvılarını korumak için geliştirdikleri bir adaptasyondur. ${ }^{6}$

\subsection{Kişiye Özgü Nedenler}

Vücut yapısı, cinsiyet, yaş, vücut kompozisyonu (özellikle kas ve yağ dokusu) gibi faktörler vücut sıvı miktarlarını etkilemektedir. ${ }^{1,2,10}$ Genel olarak iri insanlar normal insanlara göre, kas dokusu miktarı farkından dolayı erkekler kadınlara göre daha fazla miktarda vücut sıvılarına sahiptir. Benzer şekilde kas kütlesi daha fazla olan spor dallarındaki (vücut geliştirme, güreş vb.) sporcularında vücut sıvıları daha fazla olmaktadır ve vücuttaki sıvı miktarı arttıkça sıvı dengesinin sağlanmasının önemi de artmaktadır. İnsan vücudunun yaklaşık olarak \%60'ı sudan oluşmasına rağmen bu oran bireyin fizyolojik özellikleri ve spora özgü özelliklerine göre \%40-80 arasında değişebilmektedir. ${ }^{1,2}$

\section{2. Çevresel Faktörler}

Sıcak ortamlar vücut ısısın yükselmesine, nemli ortamlar ise deriden atılan terin vücuttan buharlaşarak uzaklaşmasına engel olarak vücut ısısın düşürülmesini zorlaştırır; bunun sonucunda da terleme miktarı ve sıvı kaybı artar., ${ }^{4} 13$ Ayrıca futbol, Amerikan futbolu gibi kıyafet veya koruyucular giyilen spor dallarında da terleme ile sıvı kaybında artış gözlenebilir. Terleme antrenmanlı sporcularda sedanter 
bireylere göre daha erken ve yoğun bir şekilde gerçekleşmektedir ve sıvı kaybı daha fazla olmaktadır. Çevre sıcaklığındaki artışa bağlı olarak terle kaybedilen miktar 10 kata kadar artış gösterebilir. Buna ek olarak karşılaşma sırasındaki sıvı kayıpları antremandaki kayıplara kıyasla daha fazla olmaktadır. Diğer taraftan soğuk havada yapılan kış sporlarında da solunumla kaybedilen sıvı miktarı artmaktadır. ${ }^{2}$

\subsection{Egzersiz ve Ağır Fiziksel Aktivite}

Kasların kasılması sonucu üretilen enerjinin yaklaşık olarak \%80'i ısı formundadır. Bedenimiz, sağlığımızda çok olumsuz sonuçları olan vücut ısısındaki artışı önlemek için bu ısıyı bertaraf etmelidir ve bundan dolayı vücut, aynı zamanda serinlemek için önemli sıvı kaybına sebep olan terleme mekanizmasını çalıştırmaktır. ${ }^{14}$ Egzersiz; vücut suyunun termoregülasyonu sağlamadaki görevinden ötürü, sıvı dengesinin sağlanmasını olumsuz yönde etkilemektedir. Egzersiz sonucunda vücut ısında artış meydana gelir, terleme ve terle atılan suyun buharlaşmasıyla vücut artan bu ısıyı düşürür ve vücut ısınının dengede tutulmasını sağlar bu sırada vücut sıvı dengesi bozulur. ${ }^{15}$

Egzersiz sırasında kasların ve dokuların artan oksijen ve besin ögesi ihtiyaçlarını karşılamak için kardiyovasküler fonksiyonlardaki artışa bağlı olarak kalp atım hızı ve kan basıncı artmaktadır. Kan basıncındaki artış sonucunda ise plazmada bulunan sıvının bir miktarı diğer dokulara geçmekte ve kan volümü düşmektedir. Bu kayıp egzersizin başında egzersizin şiddetine bağlı olarak gerçekleşmektedir ve egzersizin şiddetine göre plazma volümünün \%5'ine kadarı bu şekilde kayıp olabilir. Bu \%5'lik kayıp yaklaşık olarak 140 ml'ye karşılık gelmektedir. Bu miktar performansı ciddi ölçüde etkilememesine rağmen egzersizin süre ve şiddetine göre özellikle uzun süreli egzersizlerde plazma volümünde $\% 10-20$ kayıplar gerçekleşmektedir. ${ }^{2}$ Bütün bu kayıplar bir araya geldiğinde kardiyovasküler fonksiyonları olumsuz etkilemekte ve performansta düşüşle sonuçlanmaktadır. ${ }^{2,13}$

Uzun süreli veya ağır fiziksel aktivite veya egzersiz gibi durumlarda kaybedilen sıvı miktarı çok fazla olmakta ve susama hissi sıvı dengesinin sağlanmasında güvenilirliğini yitirmektedir. Sporcu rehidrate olmadan sıvı alımını durdurabilir ve bundan dolayı, susama bedenin Sıvı ihtiyaçlarının güvenilir bir göstergesi değildir. ${ }^{3}$ Üniversite öğrencilerinin sıvı tüketim alışkanlıklarının saptanmasının amaçlandığı bir çalışmaya; 678 üniversite öğrencisi dahil edilmiş ve öğrencilerin \%21,2'sinin bilinçli olarak sıvı alımına dikkat ettiği, \%3,4'ünün sadece 
susadığı zaman su tükettiği belirlenmiştir. ${ }^{16}$ Sporcuların sıvı tüketim durumlarının değerlendirilmesinin amaçlandığı 352 müsabık sporcu ile yürütülen bir çalışmada sporcuların antreman boyunca ortalama $250 \mathrm{~mL} / \mathrm{saat}$ sıvı tükettikleri ve bütün katılımcıların önerilere göre daha düşük miktarlarda sıvı aldıkları saptanmıştır. ${ }^{17}$

\section{Sıvı Dengesinin Performansa Etkisi}

SıVı dengesinin bozulmasında en etkili faktör klinik bir tablo olarak ortaya çıkan dehidratasyondur. Dehidratasyonun fiziksel ve bilişsel performansta düşüş, bilinç bulanıklığı, gastrointestinal fonksiyonların yerine getirilememesi, böbrek fonksiyonlarında bozulma, kalp fonksiyonları ve hemodinamik işlevlerde bozukluk, baş ağrısı, deri yapısının bozulması gibi çeşitli sonuçları olmaktadır. Sporcularda, özel durumlarda yada kronik hastalıkların varlığında dehidratasyonun sonuçları daha da ağıllaşmaktadır. ${ }^{6}$ Sedanter bireylerin hidrasyon sağlayabilmeleri için günde 2-3 litre (9-12 su bardağı) kadar sıvı tüketmesi önerilmektedir. Tüketilmesi gereken sıvı miktarı fiziksel aktif bireyler ve sporcularda terle kaybedilen miktarlardaki artışa bağlı olarak artmaktadır. Yapılan sporun türü, egzersizin şiddeti, süresi, hava şartları ve bireye özgü terleme faktörlerine bağlı olarak egzersiz boyunca saatte 0,3-2,4 litre (yaklaşık olarak 1-10 su bardağı) sıvı terle kaybedilmektedir. ${ }^{18}$ Hidrasyonun sağlanması sporcuların sıvı kayıplarını azaltmaları, performanslarını korumaları, submaksimal kalp atım hızlarını düşürmeleri, plazma volümlerini korumaları ve sıcağa bağlı stresten daha az etkilenmelerine neden olmaktadır. ${ }^{11,}{ }^{19}$ Dehidrasyon sonucunda hipovolemi ve hipertermi gözlenebilmektedir. Vücut sıvılarının azalması sonucu, kan hacmi azalmakta, dolayısıyla kaslara ve dokulara giden kan ve oksijen oranları da azalmakta ve performans düşmektedir. Sıvı miktarı azalınca, vücut ısısını koruyamamakta ve bu durum hipertermi yani vücut ısısının normalin üzerinde olması ile sonuçlanmaktadır. Güreş gibi ağırlık kontrolü için özellikle sıvı alımının kısıtlandığı spor dallarında hiportermi daha yaygın olarak gözlenen ölümcül bir sorundur. Vücut suyundaki her $\% 1^{\prime}$ lik azalma vücut ısısında yaklaşık olarak $0.13^{\circ} \mathrm{C}$ artışa neden olur. ${ }^{1,2}$ Sporcuların sıVı kısıtlaması gibi uygulamalarda bulunması sonucu gerçekleşen dehidratasyon kısa veya uzun dönemde ciddi riskleri de beraberinde getirmektedir. ${ }^{20}$

Dehidrasyonun önlenmesi optimal performansın sağlanmasında önemlidir. ${ }^{10}$ Sporcuların bireysel özellikleri, antrenmanlarının süre ve şiddeti, antrenman koşulları ve çevre şartlarına bağlı olarak terleme ve 
dehidrasyon düzeyleri sporcudan sporcuya farklılık göstermektedir. ${ }^{21}$ Sıvı kaybının yerine konması ve vücut sıvı dengesinin sağlanması sporcular için önemli bir sorundur; ve sıvı dengesinin sağlanmaması sporcuların sağlığı, antrenmanları ve performansları üzerinde büyük bir etkiye sahiptir. ${ }^{2}, 10$ Bisikletçilerle yapılan bir çalışmada katılımcılar 3 gruba ayrılmış, nemli ve sıcak bir ortamda submaksimal egzersiz boyunca katılımcılara terle kaybettikleri miktar kadar sıvı veya terle kaybettiklerinin yarısı kadar sıvı verilmiş ya da hiç sıvı verilmemiştir. SıVı verilmeyen grupta vücut ısısının egzersiz süresi uzadıkça daha hızlı ve daha çok arttığı ve daha çabuk yoruldukları saptanmıştır. ${ }^{14}$

Eğer sporcu antrenman yada egzersiz sırasında \%2 veya daha fazla ağırık kaybı yaşıyorsa bu sıvı alımının yetersiz olduğunun ve sporcunun daha fazla sıvı alması gerektiğinin göstergesidir. ${ }^{18}$ Yüzde iki düzeyindeki sıvı kaybı bile performansta ciddi ölçüde azalmaya neden olur; dehidrasyonun düzeyi arttıkça performansta düşüş de artar. ${ }^{21}$ Sıvı kaybına bağlı olarak aerobik kapasite ve dayanıklııık performansında düşüş olmaktadır. Özellikle sıcak ortamlarda yüzde 2 veya daha fazla vücut sıvı kaybı sonucunda VO2max oranlarında anlamlı düşüşler gözlenebilmektedir. ${ }^{2}$ Yapılan bir çalışmada $\% 3$ düzeyinde dehidrasyonun atletik performansı düşürdüğü, sporcuların daha çabuk yorulmasına neden olduğu ve oksidatif hasarı arttırdığı; kaybedilen sıvının yerine konmasıyla birlikte bu durumlarda iyileşme olduğu belirlenmiştir. ${ }^{22}$

Hipotermi durumundaki sporcuların vücut ISISI, öhidrate sporculara göre daha düşük sıcaklıklarda daha hızlı yükselmekte ve birey daha çabuk yorulmaktadır. ${ }^{2}$ Idmanlı sporcularda egzersizin süresi 90 dakikadan kısa ve çevre sıcaklığı yüksek değilse \%2'den az sıvı kayıpları tolere edilebilmesine rağmen yine de performansta düşüş ve oksidatif streste artış gerçekleşmektedir. 2, 23 Yapılan bir çalışmada uzun süreli egzersiz sırasında sıvı kaybından bağımsız olarak herhangi bir sıvı tüketilmemesinin denge ve atletik performansta düşüşe neden olduğu gözlenmiştir. ${ }^{24}$ Başka bir çalışmada ise uzun süreli egzersiz süresince sporcu içeceği tüketilmesinin sporcuların algısını olumlu yönde etkilediği gözlenmiştir. ${ }^{25}$ Diğer taraftan başka bir çalışmada düşük yoğunlukta kısa süreli egzersizlerde sporcu içeceklerinin suya kıyasla herhangi bir üstünlüğü gözlenmemiştir. ${ }^{26}$ Sporcuların sıvı tüketimine ilişkin bilgilerinin ve hidrasyon durumunun saptanmasının amaçlandığı bir çalışmada, sporcuların genelinin $(n=100)$ hidrasyon konusunda bilgisiz olduğu ve sadece \%24'ünün egzersizden önce, sırasında ve sonrasında yeterli miktarlarda sıvı tükettiği saptanmıştır. ${ }^{27}$ 


\section{Sıvı Dengesinin Korunması}

Antrenman veya müsabaka süresince yeterli hidrasyonun sağlanması optimal performansın sağlanmasına, termal stresin azaltılmasına, plazma volümünün korunmasına, yorgunluğun gecikmesine ve dehidrasyon ve terlemeye bağlı sakatlıkların önlenmesine yardımcı olur. ${ }^{11,} 28$ Sporcular kaybettikleri sıvıları yerine koymak için sıvı tüketimlerini arttırsalar da; tüketilen sıvıların gastrik boşalma ve emilme hızı, sıvı kaybetme hızından daha yavaştır. Bu nedenle sıvı kayıplarını etkin bir şekilde karşılamak zordur ve ne kadar sıvı tüketilirse tüketilsin vücut sıvılarında düşüş gerçekleşmektedir. Sporcuların antrenmanda veya müsabakalarda \%2-7 oranlarında SıVı kaybetmeleri mümkündür. ${ }^{2}$ Chlibkova ark'nın $^{29} 138$ rekreasyonel sporcu ile yaptıkları çalışmada sporcuların yarış öncesi, sırası ve sonrası özel bir sıvı alım planlarının olduğunu fakat buna rağmen sporcuların genelinde belirli oranlarda dehidratasyon, \%12'sinde hiponatremi gözlemişlerdir.

Sıvı dengesinin sağlanabilmesi için her sporcuya özgü antrenman öncesi, sırası, sonrası ve antrenman süre ve şiddetine göre sıvı ve elektrolit alım planı yapılmalı ve çevre şartları (rakım, sıcaklık vb.) veya müsabaka dönemi (antrenman sıklığındaki değişiklikler, müsabaka stresi vb.) gibi faktörler göz önünde bulundurularak gerekli değişiklikler yapılmalıdır. Alınacak sıvının ve elektrolitlerin zamanı ve miktarının sporcuya özel olarak hesaplanması son derece önemli olup; sporcunun antrenman programı ve branşına göre alması gereken sıvıya karbonhidratların ilave edilmesi gerekebilmektedir. ${ }^{2,4}$ Bazı spor branşlarında (maraton, pentatlon vb. dayanıklılık sporları) sıvı ve elektrolit alımına ek olarak karbonhidrat alımı da önemli olup, sıvıyla birlikte alınan karbonhidratların vücutta taşınması ve metabolize olması daha kolay olmaktadır. ${ }^{2}$

Vücut sıvılarının optimum düzeyde olması, antrenman veya egzersiz boyunca hidrasyonu ve optimal performansı sağlamak için sıvı ihtiyacının karşılanması için antrenman veya karşılaşmadan 24 saat öncesi son derece önemlidir. ${ }^{5,21,28}$ Egzersizden önce, sporcular daha az aralıklarla çok miktarda sıvı tüketmek yerine düzenli olarak küçük miktarlarda sıvı tüketerek iyi hidrate olmuş olmalılar. 5,13 Egzersizden 1-2 saat öncesinde tüm sporcuların yaklaşık olarak 500 $\mathrm{mL}$ sıvı tüketmeleri önerilmektedir. ${ }^{11}$

Egzersizden önce yeterli sıvı alımı, egzersiz boyunca ve sonrasında su ve sporcu içeceği tüketilmesi hidrasyonun korunmasına yardımcı 
olmaktadır. ${ }^{30}$ Antrenman ve fiziksel aktivite sırasında terle birlikte kaybedilen sıvıların yerine konması için aktivite sırasında her 15-20 dakikada bir 150-200 mL su veya sporcu içeceği içilmesi önerilmektedir. ${ }^{31}$ Özellikle bir saatten uzun süren egzersizlerde\%4-8 oranında karbonhidrat içeren içeceklerin tüketilmesi sıvı kaybını ve performansı korumada son derece önemlidir. ${ }^{30}$ Bir saatten uzun süren egzersizlerde sporcuların egzersiz boyunca $600-1200 \mathrm{~mL} / \mathrm{saat}$ karbonhidrat (30-60 gr/L) ve $\mathrm{Na}(0.5-$ $0.7 \mathrm{~g} / \mathrm{L})$ içeren içecek tüketmeleri önerilmektedir. ${ }^{11}$ Sodyum içeren sıvıların dehidrasyon sonucunda ortaya çıkan hipokinezi (hareket kabiliyetinde azalma) üzerindeki etkilerinin incelendiği bir çalışmada, egzersiz süresi ve şiddeti arttıkça sıvı kaybına bağlı olarak hipokizeni riskinin arttığı; hipokinezi geliştikten sonra ise $\mathrm{Na}^{+}$içeren sıvıların tüketilmesinin vücut hidrasyonunu ve plazma volümünü sadece su tüketenlere kıyasla anlamlı derece arttırdığı ve bunlara ek olarak sıvı dengesinin sağlanmasında etkili olan plazma renin ve aldosteron aktivitelerini de arttırdığı belirlenmiştir. ${ }^{32}$ Sodyum alımının kısıtlanmasının egzersiz sırasında hidrasyon düzeyine etkisinin incelendiği bir çalışmada da sıvı alımıyla birlikte sodyum alınmamasının hidrasyon oranını azalttığı, kalp atım hızı ve vücut sıcaklığındaki artışın azalmasında daha az etkili olduğu saptanmıştır. ${ }^{33}$ Otuz altı futbol oyuncusu ile yürütülen bir çalışmada egzersize bağlı yaşanan dehidratasyon sonrasında minarel içeren SIVı tüketiminin hidrasyon üzerinde olumlu etkileri olduğu saptanmıştır. ${ }^{34}$ Friedman ve Elliot'un ${ }^{35}$ egzersiz sırasında sporcu içeceği tüketmenin dayanıklılık performansının daha uzun sürdürülmesine neden olduğunu saptamışlardır. Dayanıklııı sporcuların antrenman veya müsabaka sırasında aldıkları sıvıların \%4-8 oranında karbonhidrat ve elektrolit içermesi önerilmektedir. ${ }^{11}$

Egzersiz sonrasında kaybedilen vücut ağırlığının 1.5 katı kadar sıvı tüketilmelidir. Egzersiz veya antrenman sonrasında sadece su yerine süt, sporcu içeceği vb. içeceklerin tüketilmesi hem kaybedilen sıvıların yerine konmasına hem de toparlanmaya yardımcı olur. ${ }^{21}$ Antrenman sonrasında kaybedilen sıvının yerine konması için bir sonraki güne kadar ortalama 3-3,5 litre su içilmesi önerilmektedir. ${ }^{36}$

\section{SONUÇ VE ÖNERILER}

Bütün bu çalışmalar sporcularda sıvı dengesinin sağlanmasının ne kadar önemli olduğunu vurgulamaktadır. Sporcuların vücut sıvı dengelerini korumak ve dehidratasyonu önelemek için her gün düzenli aralıklarla belirli miktarlarda sıvı tüketmeleri, özellikle antrenman 
öncesi, sırası ve sonrası kendi yaptıkları spor türü ve antrenman programına göre sıvı tüketim planı oluşturmaları gerekmektedir.

Pratik olarak sporcular antrenman veya karşılaşma öncesi ve sonrası tartılarak ne kadar sıvı kaybettiklerini takip edebilirler. Sporcular sıvı kayıp durumlarını değerlendirmek için idrar renklerindeki değişimleri gözlemleyerek de vücut sıvı dengeleri hakkında fikir edinebilirler.

Sıvı kayıplarının giderilmesinde süt, meyve suyu gibi diğer elektrolitleri içeren sıvılara da yer verilmesi sporcuların hidrasyon durumlarını ve atletik performanslarını korumalarına yardımcı olacaktır. Sporcular, sıvı kayıplarını yerine koymak, kasların toparlanmasını desteklemek ve ağır fiziksel aktivite yapan bireyler ve sporcular için özel olarak hazırlanan sporcu içeceklerini tüketebilirler.

Sıvı dengesinin sağlanması ve dehidratasyonun önlenmesi sporcunun performansı kadar genel sağlığının korunmasında son derece önemlidir.

\section{KAYNAKLAR}

1. European Food Safety Authority (EFSA). Scientific opinion on dietary referance values for water. EFSA Journal 2010; 8(3):1459-1497.

2. Dunford M, Doyle JA. Water and electrolytes. Nutrition for sport and exercise, 3rd ed., China: CENGAGE Learning, 2015; 240-253.

3. Gil-Antunano NP, Zenarruzabeitia ZM, Comacho AMR. Food, nutrition and hydration in sports, 1 st ed.,Madrid: Consejo Superior de Deportes, 2009; 4-26.

4. Casa DJ, Armstrong LE, Hillman SK, Montain SJ, Reiff RV, Rich BSE, Roberts WO, Stone JS. National athletic trainers' association position statement: fluid replacement for athletes. J Athl Train 2000; 35(2):212-224.

5. Grenz H. Fuel fort he body: Nutrition and athletic performance. 2010; 1-12.

6. Popkin BM, Anci KED, Rosenberg IH. Water, Hydration ve Health. Nutr Rev 2010; 68(8):439-458.

7. Jequier $E$, Consant $F$. Water as an essential nutrient: the physiological basis of hydration. Eur J Clin Nutr 2010; 64:113-123.

8. Sawka MN, Montain SJ, Latzka WA. Hydration effects on thermoregulation and performance in the heat. Comp Biochem Physiol 2001; 128:679-690.

9. Cheuvront SN, Carter R, Montain SJ, Stephenson LA, Sawka MN. Influence of hydration and air flow on thermoregulatory control in the heat. J Therm Biol 2004; 29:471-477. 
10. Singh NR, Peters EM. Artificial neural neetworks in the determination of the fluid in take needs of endurance athletes. AASRI Procedia 2014; 8:9-14.

11. Duvillard SP, Braun WA, Markofski M, Beneke R, Leithauser R. Fluids and hydration in prolonged endurance performance. Nutrition 2004; 20(7):651-656.

12. Cheuvront SN, Ely BR, Kenefick RW, Sawka MN. Biological variation and diagnostic accuracy of dehydration assessment markers. Am J Clin Nutr 2010; 92:565-573.

13. Potgieter S. Sport nutrition: A review of the latest guidelines for exercise and sport nutrition from the American College of Sport Nutrition, the International Olympic Committee and the International Society for Sports Nutrition. S Afr J Clin Nutr 2013; 26(1):6-16.

14. Kay D, Marino FE. Failure of fluid ingestion to improve selfpacedexerciseperformance in moderate-to-warmhumidenvironments. J Therm Biol 2003; 28:29-34.

15. Cheuvront SN, Ely BR, Kenefick RW, Buller MJ, Charkoudian N, Sawka $\mathrm{MN}$. Hydration assessment using the cardiovascular response to standing. Eur J Appl Physiol 2012; 112(12):4081-4089.

16. Arslan $C$, Mendeş B. Üniversitelerin farklı bölümlerinde okuyan erkek ve kız öğrencilerin sıvı tüketimleri ve bilgi düzeylerinin araştırılması. F.Ü. Sağlık Bil. Dergisi 2004; 18(3):163-170.

17. Buoite SA, Francescato MP, Sims ST, Morrison SA. Fluid intake behaviour in athletes during typical training bouts. J Sports Med Phys Fitness 2017; 57(11):1504-1512.

18. Dietiticans of Canada. Sports Hydration (Online, Available from: [https://www.dietitians.ca/Downloads/Factsheets/Sport-Hydration], (Accessed 2017 September 02).

19. Nuccio RP, Barnes KA, Carter JM, Baker LB. Fluid balance in team sport athletes and the effect of hypohydration on cognitive, technical, and physical performance. Sports Med 2017; 47:1951-1982.

20. Rees JM, Neumark-Sztainer D. Improving the nutritional health of adolescents-position statement-society for adolescent medicine. J Adolesc Health 1999; 24(6):461-462.

21. TÜBER (2016) Türkiye Beslenme Rehberi. T.C. Sağlık Bakanlığı Yayın No: 1031, Ankara.

22. Paik IY, Jeong MH, Jin HE, Kim YI, Suh AR, Cho SY, Roh HT, Jin CH, Suh $\mathrm{SH}$. Fluid replacement following dehydration reduces oxidative stres during recovery. Bioche Biophys Res Commun 2009; 383:103-107. 
23. França $M B$, Panek $A D$, Eleutherio ECA. Oxidative stres and its effects during dehydration. Comp Biochem Physiol 2007; 146:621-631.

24. Erkmen N, Taşkın H, Kaplan T, Sanloğlu A. Balance performance and recovery after exercise with water intake, sport drink intake and no fluid. J Exerc Sci Fit 2010; 8(2):105-112.

25. Ali A, Duizer L, Foster K, Grigor J, Wei W. Changes in sensory perception of sports drinks when consumed pre, during and post exercise. Physiol Behav 2011; 102:437-443.

26. Hill RJ, Bluck LJC, Davies PSW. The hydration ability of three commercially available sports drinks and water. J Sci Med Sport 2008; 11:116-123.

27. Judge LW, Kumley RF, Bellar DM, Pike KL, Pierson EE, Weidner T, Pearson D, Friesen CA. Hydration and fluid replacement knowledge, attitudes, barriers, and behaviors of NCAA division 1 american football players. J Strength Cond Res 2016; 30(11):2972-2978.

28. Evans GH, James LJ, Shirreffs SM, Maughan RJ. Optimizing the restoration and maintenance of fluid balance after exercise-induced dehydration. J Appl Physiol 2017; 122:945-951.

29. Chlibkova D, Nikolaidis PT, Rosemann T, Knechtle B, Bednar J. Reported hydration beliefs and behaviors with out effect on plasma sodium in endurance athletes. Front Physiol 2017; 8:1-11.

30. Burke LM. Nutritional needs for exercise in the heat. Comp Biochem Physiol 2001; 128: 735-748.

31. American College of Sports Medicine (ACSM) [Online]. Selecting and effectively using hydration for fitness. Available from: [http://www.acsm.org/], (Accessed 2017 September 09).

32. Zorbas YG, Petrov KL, Vladimir LY, Vassily JK, Vladimir KP, Victor AD. Effect of fluid and salt supplementation on body hydration of athletes during prolonged hypokinesia. Acta Astronaut 2002; 50(10):641-651.

33. Koenders EE, Franken CPG, Cotter JD, Thornton SN, Rehrer NJ. Restricting dietary sodium reduces plasma sodium response to exercise in the heat. Scand J Med Sci Sports 2017; 27:1213-1220.

34. Chycki J, Zajac T, Maszczyk, Kurylas A. The effect of mineral-based alkaline water on hydration status and the metabolic response to shortterm anaerobic exercise. Biol Sport 2017; 34:255-261.

35. Friedman R, Elliot AJ. Exploring the influence of sports drink exposure on physical endurance. Psychol Sport Exerc 2008; 9:749-759.

36. Göğüş U. Mutluluğa doğru gıda-spor ve sağlık. Ankara: Pelikan Yayıncılık, 2003; 1. Baskı. 